1 Exploring the parents' attitudes and perceptions about school breakfast to understand why

2 participation is low in a rural, Midwest state

\title{
INTRODUCTION
}

\section{Importance of School Breakfast}

5 The school environment is an important setting for focused public health efforts because

6 schools offer relatively consistent and extensive contact with a large number of youth in the

7 United States. The food environment of a school has a powerful influence on students' eating

8 behaviors, including those related to breakfast. ${ }^{1}$ Many children and adolescents do not eat

9 breakfast on a regular basis, despite the evidence that breakfast is associated with lower risks of

10 obesity and chronic disease and correlated with improved cognitive and motor function and

11 better achievement in school ${ }^{2,3}$. Estimates of youth skipping breakfast have ranged from about

$1210 \%-30 \%$, depending on the definition and methodology used to collect data. ${ }^{2}$ The National

13 Health and Nutrition Examination Survey (NHANES; 1999-2006) found that approximately 20\%

14 of children and $31.5 \%$ of adolescents in the U.S. regularly skip breakfast. ${ }^{3}$

15 Both the National School Lunch Program (NSLP) and National School Breakfast

16 Program (SBP) support the health and well-being of youth by providing millions of children with

17 one to two nutritious meals per day. In its current state, the SBP serves mainly as a safety net for

18 the nation's most economically vulnerable students. The program helps offset the burden faced

19 by many families experiencing food insecurity by providing a low-cost or free nutritious meal

20 each morning. Of more than 12.1 million children who participated in the SBP during FY 2011,

21 over 10.1 million were eligible for free or reduced-price meals, the threshold for which is a

22 household income less than $185 \%$ of the federal poverty level. ${ }^{4}$

The SBP has the potential to enhance health and academic achievement among students

24 and has been shown to improve nutrition outcomes in children in low-income households, a 
25 group with historically high rates of participation in the program. ${ }^{5}$ The program reduces the

26 chance that a student will skip at least one breakfast per week and increases the probability that

27 low-income children will eat breakfast in the morning. ${ }^{6}$ Children who eat breakfast at school

28 consume more fruit and milk and a wider variety of foods than children who do not eat breakfast

29 or who eat breakfast at home. ${ }^{5}$ A pilot program in Maryland, in which schools offered in-

30 classroom breakfast to all students, resulted in significantly higher rates of breakfast eating,

31 lower rates of tardiness, and fewer suspensions for disciplinary incidents compared to schools

32 without the universal breakfast program. ${ }^{7}$

\section{SBP Participation}

SBP participation rates are relatively low throughout the U.S., and particularly in the

35 Midwest and West regions and children are not eating breakfast at home. One study indicated

36 that rural adolescents reported eating breakfast with their families only 1-3 times a week. ${ }^{8}$ Even

37 with its potential to enhance students' health and academic achievement, the SBP is widely

38 underutilized compared with the NSLP. Approximately $90 \%$ of schools that offer school lunch

39 also offer school breakfast; ${ }^{9}$ however, the SBP only serves about one-third of the children served

40 by the NSLP. ${ }^{10}$ Among low-income children, the proportion jumps to about half. ${ }^{9}$ Participation

41 in the SBP is almost completely limited to the subset of students who already eat school lunch

42 regularly. ${ }^{6}$ Unlike the NSLP, participation in the SBP is heavily skewed towards students who

43 are eligible for subsidized meals. On average, $39 \%$ of students who are eligible for free meals eat

44 breakfast at school, compared to $20 \%$ of students eligible for reduced-price meals, and only $8 \%$

45 of students who pay full price. ${ }^{6}$ Nevertheless, a significant proportion of low-income children

46 who have access to the program still do not participate, including $35 \%$ of children who are food 
47 insecure. ${ }^{6}$ These figures point to extensive room for improvement in SBP implementation

48 nationwide.

For the 2013-2014 school year (SY), five of the states with lowest SBP participation were

50 rural states in the Midwest and West, including the state of Iowa. ${ }^{11}$ Although the vast majority of

51 schools in Iowa offer the SBP, participation rates are significantly lower than in other states. ${ }^{9}$

52 Only $40.1 \%$ of low-income students in Iowa who eat lunch at school also eat school breakfast, 53 compared to $53.2 \%$ nationally. ${ }^{9}$

\section{Factors in Low SBP Participation}

55 In general, little is known about why school breakfast participation rates are low, and

56 even less is known about the factors related to low participation in the lowest-performing states.

57 Possible factors that have been identified have not been substantiated in a quantitative study nor

58 examined in a rural, low-participation state. For example, bus schedules have been identified as a

59 major obstacle to SBP participation, ${ }^{12}$ which is an issue that may be exacerbated in rural school

60 districts, with their wider geographic reach. Other identified barriers to SBP participation have

61 included inadequate time provided by schools, resistance from teachers and administrators to

62 alternative serving models (e.g., breakfast in the classroom), the stigma attached to eating

63 breakfast at school, and costs associated with the program. ${ }^{12}$ Focus groups with administrators,

64 school food service directors, parents, and students in both rural and urban school settings ${ }^{13}$ have

65 revealed these concerns, as well as the opinion that breakfast is first and foremost a parental

66 responsibility. Attitudinal barriers ${ }^{14}$ and policy, systems and environmental barriers from

67 perspective of high school students have been examined. ${ }^{15}$

68 Previous studies have not examined SBP perceptions in depth and from a rural

69 perspective. They have either focused broadly, on national data, or on a small sample of 
70 qualitative data. Additionally, research on school meals in general and breakfast in particular is

71 lacking in the wake of the Healthy, Hunger-Free Kids Act of 2010 that mandated dramatic

72 reforms to school nutrition guidelines. ${ }^{4}$ No research that postdates the reforms is available on

73 SBP changes unrolled during SY 2013-2014 and parent perceptions of SBP. It is therefore

74 valuable to more rigorously investigate factors related to low SBP participation. Rural schools in

75 particular may benefit from this research, as they may face unique structural and attitudinal

76 barriers to raising SBP participation.

77 This study was part of a larger, statewide study examining school breakfast participation

78 that included data collections with high school students and school administrators. The study

79 explored factors that are related to low school breakfast participation in one rural, Midwest state.

80 Previous published studies have not quantitatively measured the relationship between parental

81 factors (knowledge, perceptions and attitude) and SBP participation. Additionally this study

82 examines these relationships with a focus on rurality. Specifically, the study set out to understand

83 parents' knowledge and perceptions about school breakfast, including reasons for participation,

84 and ideas for improving participation and identify family- and district-level characteristics that

85 are significantly associated with school breakfast participation.

\section{METHODS}

\section{Participants and Recruitment}

The study sample consisted of parents of school-aged children (grades pre-kindergarten

89 through 12) in a mid-sized, rural, Midwest state. The state Department of Education encouraged

90 school districts and schools to distribute a link to an online survey via email, the school or

91 district website, and as part of regular communications sent home to parents. Respondents were

92 also encouraged to share the survey link with their social networks after they completed the 
93 survey. A total of 8,983 parents completed the survey, representing 231 of the state's 338 school

94 districts. After eliminating parents reporting on a child younger than $1^{\text {st }}$ grade, there were 8,228

95 parents from 222 districts. Parents that did not identify a school district were also deleted,

96 leaving 7,209 parents for the analysis.

97 A university Institutional Review Board reviewed and approved this study. The first page

98 of the survey presented parents with the elements of consent. Returning the survey was

99 considered consent. No compensation was provided to respondents.

\section{Measures and data cleaning}

The online survey instrument was jointly developed by researchers at a university public

102 policy center and program staff at the state Department of Education, Team Nutrition. The

103 survey was designed to collect statewide data to provide policy and program developers with

104 information about parental knowledge and perceptions. To guide survey formation, researchers

105 conducted a scan of the literature on school breakfast participation, although previous research to

106 specifically elicit parent beliefs and attitudes around school breakfast was found to be scant.

107 Nevertheless, survey items and topical areas were influenced by assessment instruments from the

108 USDA's Discover School Breakfast Toolkit, ${ }^{16}$ the University of Mississippi's National Food

109 Service Management Institute ${ }^{17}$ and published studies. ${ }^{13,18,19,20}$ Qualtrics $^{\circledR}$ online survey software

110 was used to field the survey from December 2014 to February 2015.

111 Respondents were asked to provide information about the grade level and school district

112 of their oldest school-age child (no other demographic data were collected). The oldest child was

113 selected as the target for the study in order to ensure that sufficient number of parents of high

114 school aged children participated in the survey. They identified whether their oldest child's

115 school currently served school breakfast. Parents who reported that breakfast was served were 
116 asked to estimate the cost of a school breakfast at that school, based on values between $\$ 0.00$ and

$117 \$ 10.00$ or "do not know."

118 Parents could indicate if their child ate breakfast in the past week "every day," "most 119 days," "sometimes," "never," or "I don't know." They also reported on the frequency of their 120 child's breakfast consumption in a variety of specific settings, such as home, school, on the way 121 to school, and at daycare (if applicable). Parents were asked to rate the importance of breakfast 122 relative to other meals of the day and who they felt was responsible for providing breakfast for 123 their child - the parent, the child, the child's school, or a babysitter/daycare provider.

$124 \quad$ Using a skip logic pattern embedded in the survey, parents were asked about reasons why 125 their child does or does not participate in school breakfast, depending on the parent-reported 126 frequency of child's school breakfast participation the previous week. Parents with a child who 127 ate school breakfast in the previous week were asked to select all that applied from a menu of 128 reasons why they ate school breakfast (for example, "My child likes school breakfast"). Parents 129 with a child who "never" ate school breakfast in the previous week were excluded from these 130 questions. Conversely, parents who reported that their child "never" ate school breakfast in the 131 previous week were asked to mark all that apply from a separate menu of reasons why their child 132 did not eat school breakfast (for example, "It is too hard to get my child or children to school 133 early enough for breakfast"). Parents with a child who ate school breakfast "every day" in the 134 previous week were excluded from responding to these "why not" questions. Both sets of 135 questions included an "other" option for open-ended responses.

136 Closed-ended items addressed possible benefits to eating school breakfast, whether 137 parents would support their child wanting to eat school breakfast in the future, a reasonable cost 138 for school breakfast, and the perceived health value of school breakfast. Parents were also asked 
139 to speculate on the SBP's intended target audience. Parents could check all that apply for the

140 intended target audience including, children whose families a) do not have the time, or b) do not

141 have the money, or c) do not care enough to provide breakfast at home. Other response choices

142 regarding target audience were d) student athletes or e) all children in the district. To determine

143 how important parents viewed breakfast as a meal compared to other meals, we asked parents to

144 indicate if breakfast was 1) the most important meal, 2) an important meal but NOT always

145 eaten, 3) as important as other meals, or 4) a meal that could be skipped.

146 Finally, two open-ended items were used to elicit: 1) changes to the SBP that would

147 attract their child to eat breakfast at school, and 2) why they believed SBP participation rates in

148 the state was low relative to rates of school lunch participation.

149 Respondents' school districts (identified by respondents) were coded for district size,

150 urban-rural locale, district free and reduced-price lunch percent participation, and district school

151 breakfast participation rates for SY 2014-2015. Districts were categorized as large (enrollment of

152 2,500 students or more), medium-sized (1,000-2,499 enrolled), or small ( $<1,000$ enrolled). The

153 decision to use these categories was based on the precedent of a previously published study,

154 conducted in the same state. ${ }^{21}$

155 The National Center for Education Statistics classifies U.S. school districts with 12

156 urban-centric locale codes based on matching the physical location of the school district office

157 against geographic and population data from the U.S. Census Bureau. ${ }^{22}$ This classification

158 system was used to define rurality.

159 A total benefits score based on parents' identification of the benefits of school breakfast

160 was calculated. Instead of considering benefits individually, a total score or index was created 
161 from the number of questions about possible benefits that the parent answered yes to, out of 11 162 total questions.

163 Missing data was handled through multiple imputation, which was employed using the

164 MI procedure within SAS software (Copyright @2013, SAS Institute Inc. SAS and all other SAS

165 Institute Inc. product or service names are registered trademarks or trademarks of SAS Institute

166 Inc., Cary, NC, USA). ${ }^{23}$ Ten imputation datasets were generated which imputed missing data for 167 whether or not the student utilized school breakfast (673 of 7209 values imputed), the parent's

168 perception of school breakfast importance (594 values imputed), the urbanity of the school 169 district of the student (91 values imputed), the size of the school district of the student (314 170 values imputed), the total score of benefits questions (19 values imputed), parent perception of 171 school breakfast healthiness (984 values imputed) and lastly the district free and reduced 172 breakfast percent (128 values imputed). The imputed values were constrained to be within the 173 range of zero to one for binary and proportion variables and zero to eleven for total score on 174 benefits questions. Additionally, the variables grade and five parent perception variables of who 175 school breakfast is intended to help had no missing values but were included in the MI 176 procedure.

177 Binary variables were created from categorical variables in order to implement the MI 178 procedure; this resulted in fractional imputed values in the ten imputation datasets due to the 179 multivariate normality assumption of the MI procedure. Multiple data cleaning steps were taken 180 to ensure that the imputation datasets were usable for analysis; note that all imputation cleaning 181 steps were performed on each imputation dataset separately. First, the binary variable whether or 182 not the student utilizes school breakfast was utilized was rounded to either zero or one so that 183 imputed values greater than or equal to 0.5 are rounded to one and references therein states that 
184 many texts suggest rounding imputed values for binary variables whereas others suggest that this

185 produces biased results, in particular when the true proportion is close to zero or one. ${ }^{24}$

186 Continuous variables were imputed using a Markov chain Monte Carlo (MCMC) method. The

187 imputed values total score of benefits questions was rounded to the closest integer between zero 188 and eleven.

189 Categorical predictors included parent perception of school breakfast healthiness and 190 parent perception of importance of school breakfast versus other meals. Adjusting these imputed

191 values was a little bit more difficult because there are three or more categories and exactly one 192 must equal one whereas the others must equal zero. For these variables, the category with the 193 highest fractional imputed value was set to one and the other categories were set to zero.

194 Some predictors are district level characteristics, therefore we wanted to ensure they were 195 the same across district; they are rural code, size of district and district free and or reduced 196 breakfast percentage. For rural code, a binary variable, the imputed values within a district were 197 averaged then rounded; all observations within the district were assigned this value. For district 198 free and or reduced breakfast percentage, all observations within a given district also share the 199 mean value. For size, a three level categorical variable, each observation was initially assigned a 200 separate district size based on whether size small, medium or large received the largest imputed 201 value. Within a district the district size with the most "votes" was assigned as the overall district 202 size for all observations sharing that district.

203 Data Analysis

204 The responses to the open-ended questions were printed out and read by the first, second 205 and fourth authors. These authors developed a list of codes based on the responses and the fourth 
206 author coded each response. Quotes that were representative of the most frequent codes are 207 presented in the results section.

208 Generalized Estimating Equation models (GEE) were fit to the data. ${ }^{25,26}$ The link and 209 variance function were chosen to mimic logistic regression. The working correlation structure 210 chosen was compound symmetry; this implied that students from the same district are all 211 correlated equally and students from different districts are independent. The response variable 212 was respondent self-report of their oldest school-age child eating school breakfast or not in the 213 previous week. The logit of the probability of that event was modeled as a function of the 214 following predictors: size of school district, district free/reduced lunch participation, total 215 benefits score, rurality of school district, parent perception of importance of breakfast, parent 216 perception of healthiness of breakfast, grade, and whether or not the parent believed that school 217 breakfast is 1) intended to help parents with no time, 2) intended to help parents with no money, 218 3) intended to help parents who do not care, 4) intended to help student-athletes, or 5) intended 219 to help all students. We also considered interactions of these predictors in the model. 220 The form of the model is:

222 where

$$
\operatorname{logit}\left(\pi_{\text {school breakfast }}\right)=\boldsymbol{X}^{T} \boldsymbol{\beta}
$$

$\pi_{\text {school breakfast }}=$ probability of utilizing school breakfast $\mathbf{X}=$ vector of household and district-specific predictors $\boldsymbol{\beta}=$ vector of parameters corresponding to household and district-specific predictors

227 utilizing the MIANALYZE procedure in SAS software. The variable selection procedure 228 mimicked backward selection based on p-value; the starting model included all the variables, all 229 variables interacted with grade and all variables interacted with urban indicator. The ten GEE 
230 models were run and removal of effects was based on the aggregated p-value of the imputations

231 as reported by the MIANALYZE procedure. All main effects were left in the model regardless of

232 p-value; backward selection continued until all remaining interaction effects had p-values less

233 than 0.05. A similar backward selection approach was employed using backward selection based

234 on the quasi-likelihood information criterion (QIC) value averaged over the ten imputed

235 datasets. ${ }^{27}$ The result was the same model with five more interaction effects; the effects were

236 nearly identical in direction and very similar in magnitude. The reduction in QIC with this model

237 was relatively small, therefore the original model based on p-value backward selection was

238 chosen due to parsimony.

\section{RESULTS}

240 Characteristics of Districts and Respondents

241 Table 1 provides descriptive statistics for key variables. After dropping the

242 aforementioned exclusions due to certain types of missing data, 221 school districts remained in 243 the sample. Of those, 154 were classified as rural and 60 as urban. Most of the school districts

244 (133 districts or 60.18\%) in this study were small (less than 1,000 students), 18.10\% (40

245 districts) were medium-sized (1,000-2,499), and 11.31\% (25 districts) were large (more than

2462,500 students). The districts' average student participation rate in the free and reduced lunch

247 program was $38.80 \%(\mathrm{SD}=48.73 \%)$. The average level of student SBP participation for the

248 districts was $19.55 \%$ ( $\mathrm{SD}=10.65 \%)$. The greatest proportion of respondents $(54.5 \%)$ was from

249 rural districts and districts with an enrollment of $<1,000$ students $(38.3 \%)$.

250 Knowledge and Perceptions of School Breakfast

251 The majority of parent respondents (89.9\%) reported that their oldest school-age child's 252 school does serve breakfast, which is indicative of the state requiring breakfast to be served at all 
253 schools. When asked to estimate the cost of a breakfast at their child's school, their responses

254 averaged $\$ 1.74(\mathrm{SD}=0.44 ; \min =1.00, \max =2.00)$. Many parents acknowledged the

255 importance of breakfast for their child. Over one fourth $(27.44 \%)$ stated that breakfast is the

256 "most important meal of the day," another 17.23\% agreed that "it's important, but my child

257 doesn't eat it every single day," while $43.21 \%$ considered breakfast “just as important as any

258 other meal."

259 Almost one fourth of parents (24.72\%) felt there were no benefits to their family from

260 participating in school breakfast. However, "there are no benefits" was only added as a response

261 option after the survey had been live for several weeks, at which point nearly 2,000 respondents

262 had already completed it. Therefore, this result may underestimate the actual proportion of

263 respondents who perceive no benefits to school breakfast participation.

264 Respondents did identify positive aspects of school breakfast, believing that school

265 breakfast would give their child a more nutritious meal (17.42\%), that school breakfast offers

266 food their child likes (17.51\%), and that school breakfast would mean their child was not hungry

267 in the morning (19.49\%). Convenience was the most prominent perceived benefit. Respondents

$268(45.5 \%)$ agreed that school breakfast was convenient, and about one-quarter believed that it

269 would make their mornings less stressful (25.4\%) and would give them more time in the morning

$270(22.68 \%)$. Of the parents who reported that their child did not eat school breakfast, $71.15 \%$

271 indicated that they would support their child if he or she wanted to.

272 When asked whom they believed the SBP was intended to help, almost half of

273 respondents identified children whose parents did not have the time (48.48\%) or money

$274(49.38 \%)$ to provide breakfast at home, and almost one-third agreed it was for children whose

275 parents "don't care enough" to provide breakfast $(32.70 \%)$. One in five of respondents $(21.36 \%)$ 
276 believed the SBP is intended to help student-athletes, and $47.68 \%$ believed it is intended to help

277 all children in the school district.

278 Responses were divided when parents were asked to rate the health value of school

279 breakfast. Over one third (39.46\%) considered school breakfast to be healthy, while only $15.80 \%$

280 believed it was not healthy, and $31.09 \%$ responded that they "do not know" if school breakfast is

281 healthy or not. Less than half $(44.81 \%)$ believed breakfast at school and at home to be equally

282 healthy, with only $10.72 \%$ believing that breakfast at school is healthier.

\section{Reasons for SBP Participation}

284

285

286

287

288

289

290

291

292

293

294

295

296

297

298
When parents were asked to respond to statements about why their child did or did not eat school breakfast, the most frequently cited reasons for not eating school breakfast were the child preferring to eat at home $(32.28 \%)$, the belief that feeding children is a parental responsibility $(19.86 \%)$, the child not liking school breakfast (18.82\%), the child being responsible for breakfast (13.15\%), the cost of school breakfast being too high (13.14\%), the timing of school breakfast not fitting the family schedule (12.80\%), and the child not getting to school early enough for breakfast $(12.51 \%)$. Few parents indicated the following reasons for their child not eating school breakfast: the child gets him/herself to school $(9.14 \%)$, they eat breakfast as a family (8.56\%), they do not want the government to feed their children (4.05\%), or the parent would be embarrassed $(0.72 \%)$ and fear other parents would judge them $(0.65 \%)$. Parents also provided reasons they believed school breakfast participation is low in the state. Timing factored into many responses; for example, some indicated that their child preferred to eat first thing in the morning instead of waiting to get to school. Also, many rural parents in particular reported that district bus schedules made it difficult for their children to be at school in time for breakfast. As one parent stated, "The large areas the district encompass 
299 make for longer bus rides and less time at school in the morning to actually sit and eat

300 breakfast..."

301 Some parents expressed opinions about the value that rural families place on eating

302 together, eating at home, or participating in government programs. One parent explained why

303 eating at home was important to her,

304 I prefer that my kids eat at home where I can control what they are eating. Also, I know I

$305 \quad$ can provide a healthy breakfast at home vs. I am less sure what they offer at school

306 breakfast. We make time to sit down and eat breakfast daily together. That is our

$307 \quad$ preference as a family.

308 Another parent articulated a shared value about being together as a family, "As a farming state I

309 feel that we do more family things in our state, so I feel that it's because families do things or

310 because we raise our children to be more independent so they can provide for themselves."

311 Opinions about the role of government were also expressed, "Because we don't expect the

312 government to take care of our kids....that the parent's job!!!!!!” One parent summed up many

313 parents perceptions with the following quote,

$314 \quad$ Because in Iowa we do not expect the schools (government) to provide for our children's breakfast. Breakfast is a family time experience. Also, being so rural, many older students are up for chores and/or sports practice before school and to wait until school would mean being hungry for a while before starting their day. Instead they eat when they get up and before chores, work, or practices.

\section{Suggestions for Improving SBP}

In response to an open-ended item, parents identified changes that they believed would

321 attract their child to eat breakfast at school. Many proposed changes focused on existing 
322 logistical barriers, such as bus or academic schedules that prevent children from getting to school 323 early enough for breakfast. "School would need to start later. She is not going to get up so much 324 earlier to be at school longer in the day," according to one parent. Other responses reflected the 325 need for schools to consider children's preferences and serve a variety of foods that appeal to 326 students, such as "Having more choices to choose from. Often times my child would want only 1

327 item like the donut but nothing else." Some parents responded in accord with their perception of 328 school breakfast as not healthy, such as "My child wants to eat school breakfast but currently it 329 is sugar cereals and at least one ingredient has high fructose corn sugar and/or food colorings.

330 Not appropriate for ideal brain food."

\section{Factors Associated with School Breakfast Participation}

Table 2 displays all parameter estimates and standard errors for the GEE model. Each one 333 percentage point increase in a district's free and reduced lunch participation rate corresponds to a 3340.0143 change in the log odds of eating school breakfast $(\mathrm{p}=.0005)$. Framed in terms of odds 335 ratio interpretation, holding all other predictors constant each one percentage point increasing a 336 district's free and reduced lunch participation rate increases the odds of school breakfast

337 utilization by a factor of $\mathrm{e}^{\wedge} 0.014284=1.01439$ or equivalently, increases the odds of school 338 breakfast utilization by $1.439 \%$.

339 Each unit increase in the total score of benefits corresponded to a 0.382 change in the log 340 odds of eating school breakfast $(p<.0001)$. Children whose parents believed that school

341 breakfast is intended to help parents with "no time" had a change in log odds of eating school

342 breakfast of $-0.316(p<.0001)$. Children whose parents believed that school breakfast is

343 intended to help parents with "no money" had a change in log odds of eating school breakfast of $344-0.287(p=.002)$. Students whose parents believed that school breakfast is intended to help 
345 parents who "don't care" had a change in log odds of eating school breakfast of -0.426 ( $p<$

$346.0001)$. Students whose parents believed that school breakfast is intended to help student athletes

347 had a change in log odds of eating school breakfast of $0.353(p<.0001)$.

348 In order to interpret the effects of urban and parent perception of school breakfast

349 healthiness, the main and interaction effects must be considered simultaneously. The Table 3

350 illustrates how parent perception of school breakfast healthiness affects the logit of school

351 breakfast participation for rural versus urban school districts. Each cell mean is the mean

352 estimated by the model. The table summarizes the main effects of parent perception of school

353 breakfast healthiness, school district rurality and their interaction. The reference group is families

354 with parents who don't know if school breakfast is healthy and attend a school district in a rural

355 area. The effect of families with parent perception that school breakfast is healthy in urban

356 school districts corresponds to a 0.262 change in the log odds of eating school breakfast. The

357 effect of families with parent perception that school breakfast is not healthy in urban school

358 districts corresponds to a -0.010 change in the log odds of eating school breakfast. The effect of

359 families with parents who do not know if school breakfast is healthy or not in urban school

360 districts corresponds to a -0.610 change in the log odds of eating school breakfast. The effect of

361 families with parent perception that school breakfast is healthy in rural school districts

362 corresponds to a 0.533 change in the log odds of eating school breakfast. The effect of families

363 with parent perception that school breakfast is not healthy in rural school districts corresponds to

364 a 0.327 change in the log odds of eating school breakfast.

365 In order to interpret the effects of grade and school district size, the main and interaction

366 effects must be considered simultaneously. The Figure 1 illustrates how grade affects the logit of

367 school breakfast participation for different size school districts. The reference group is small 
368 school districts which corresponds to a 0.019 change in the log odds of eating school breakfast

369 for each one unit increase in grade (this is reflected in the positive slope of the black line). The

370 effect of going to a medium size school district corresponds to an initial -0.232 change in the log

371 odds of eating school breakfast (shift the intercept downward) and a 0.022 change in the log odds

372 of eating school breakfast for each one unit increase in grade (slight increase in the slope). The

373 effect of going to a large size school district corresponds to an initial 0.266 change in the log

374 odds of eating school breakfast (shift the intercept upward) and a -0.065 change in the log odds

375 of eating school breakfast for each one unit increase in grade (the slope is now negative). The

376 results are summarized in the Figure 1; the reference line (black) is small school districts. The

377 effect of going to a medium sized school corresponds to an initial change in the intercept as well

378 as change of slope in terms of the effect on the logit of eating school breakfast.

379 In sum, the following factors were positively associated with school breakfast

380 participation: 1) parental perception of the benefits of school breakfast, 2) the belief that

381 breakfast is important relative to other meals, and 3) parental perception of the healthfulness of

382 school breakfast, 4) the proportion of students in a district that participate in the free or reduced

383 price school meals, and 5) the belief that school breakfast is intended to help athletes.

384 Conversely, the following factors were negatively related to school breakfast participation: 1)

385 parental perception that school breakfast is intended for children of parents who do not have the 386 time or money or "don't care enough" to serve breakfast at home and 2) urban locations.

\section{DISCUSSION}

Although parents are important stakeholders in child nutrition, little research has been

389 done to identify barriers and facilitators to SBP participation from the parent perspective, nor 390 have the unique challenges that may be faced by families living in rural, Midwest and Western 
391 states been studied. Families in these areas may subscribe to values related to school meals that

392 are different from their urban or suburban counterparts. This study attempted to better understand

393 the attitudes toward and perceptions of the SBP among Midwestern parents of school-aged

394 children in a rural state, as well as to identify policy, systems and environmental barriers to

395 participation. Specifically, the study investigated what these parents knew about school

396 breakfast, the perceptions they held about the SBP, and their reasons for SBP participation or

397 non-participation. The study also examined how the factors parents reported were associated

398 with school breakfast participation.

399 Normative perceptions about school breakfast appear to be associated with participation.

400 The analysis indicated that holding the belief that the SBP is for children whose parents do not

401 have enough money, or time, or "don't care enough" to provide breakfast at home is a negative

402 predictor of participation. Responses from parents in this study also suggest a distinct set of

403 values that may contribute to low rates of SBP participation; many associated school breakfast

404 with poverty and with the stigma of being on government assistance. Previous research is

405 consistent with this finding. ${ }^{6,13}$ Moving forward, state and district officials might consider

406 implementation plans for school breakfast that function to reduce stigma, such as universal SBP

407 availability. By providing free school breakfast to all students, low-income students may no

408 longer be singled out as such by their SBP participation alone. ${ }^{28}$

$409 \quad$ From a policy, systems and environmental perspective, school breakfast participation in

410 low-participation areas may involve a convergence of factors at an administrative level and at an

411 individual level, so future interventions and policy changes targeted at increasing SBP

412 participation should address barriers to participation at multiple levels. Our findings supported

413 previous research ${ }^{12}$ in identifying bus schedules that fail to accommodate school breakfast as a 
414 major obstacle to SBP participation, ${ }^{12}$ and transportation issues may be exacerbated by the

415 geographic reach and relatively fewer administrative resources of rural school districts.

416 There are important limitations to this study. Data on SBP participation are based on

417 parent self-report, which may not accurately reflect true rates of participation among children of

418 respondents. Because parents with strongly positive or negative opinions about school breakfast

419 and/or school meals may have been more likely to participate in the survey, selection bias may

420 have distorted the findings of this study. In addition, results from this online survey are cross-

421 sectional and therefore the direction of relationships found between SBP participation and other

422 factors is unable to be determined. It is also not clear how the missing data and dropped cases

423 may have biased results.

IMPLICATIONS FOR RESEARCH AND PRACTICE

Parents in this study identified several logistical or structural barriers that made SBP

426 participation the less desirable choice for their family. One theme was related to scheduling.

427 Offering breakfast at times other than before school may prove to be especially appropriate for

428 rural districts, where the geographic spread of students may realistically prevent alterations to

429 bus schedules. Previous research has demonstrated that incorporating breakfast into the school

430 day is a promising approach to increasing SBP participation. ${ }^{11}$ One strategy that has been used

431 successfully is moving breakfast to the classroom after school has started. ${ }^{6,7}$ In-classroom school

432 breakfast has been shown not only to increase participation rates, ${ }^{20,28}$ but also to lead to

433 significant improvements in student behavior and/or academic performance, especially among

434 low-performing, free-lunch eligible, Hispanic, and low-BMI students. ${ }^{29}$

435 Administrative approaches that facilitate program participation may also enhance its

436 convenience for the families in this study. For example, offering breakfast to all children has 
437 been shown to increase SBP participation, in part by eliminating the need for parents to fill out

438 meal applications and submit payments. ${ }^{28}$ Universal breakfast would be an option for districts

439 that qualify for the Community Eligibility Provision established under the Healthy, Hunger-Free

440 Kids Act of 2010. This federal support allows high-poverty districts and schools to offer

441 breakfast at no cost to all students without the need for parents to administratively enroll. ${ }^{9}$ For

442 some low-income families, direct certification allows children who already participate in

443 government assistance programs like Supplemental Nutrition Assistance Program or Temporary

444 Assistance for Needy Families to automatically qualify for free breakfast without additional

445 documentation from parents. ${ }^{9}$ These strategies alone or in conjunction with each other have been

446 shown to increase SBP participation..$^{9,20,28}$

447 At the parent or individual family level, communication campaigns may be influential for 448 addressing factors we found associated with low SBP participation. A campaign focused on the 449 importance of breakfast, the benefits of school breakfast participation, dispelling misperceptions

450 and the nutritional and cost advantages of school breakfast could target those beliefs identified as

451 significant by the model used in this study. Highlighting the benefits of school breakfast that

452 were most relevant to the families in our study (for example, more time and less stress in the

453 morning before school, the convenience of breakfast at school) could increase their perception

454 that participation is a positive behavior. Previous research indicates that parents hold many

455 misperceptions around the nutritional value of school meals, often perceiving school food as

456 unhealthy or unappetizing to children. ${ }^{30}$ Parents may be making assumptions about the type of

457 food served and may not be aware of the true nutritional content of school breakfast.

458 Communicating with parents about school breakfast nutrition could encourage them to perceive

459 it as an option for nourishing their child in the morning. 
461 low-income families in stretching their food budget, but participation remains very low in some 462 areas of the U.S. This exploratory study, conducted in an area with low SBP participation, 463 identified some attitudes and beliefs related to school breakfast from the parent perspective, 464 along with factors predictive of SBP participation. Future research should investigate how 465 community norms, beliefs, and attitudes can be targeted for change to encourage participation in 466 school breakfast programs.

467 


\section{REFERENCES}

471 1. Kubik MY, Lytle LA, Hannan PJ, Perry CL, Story M. The association of the school food

472 environment with dietary behaviors of young adolescents. Am J Public Health. 2003; 93(7):

$473 \quad 1168-1173$.

474 2. Boschloo A, Ouwehand C, Dekker S, et al. The relation between breakfast skipping and

475 school performance in adolescents. Mind Brain Educ. 2012; 6(2): 81-88.

476 3. Deshmukh-Taskar PR, Nicklas TA, O'Neil CE, Keast DR, Radcliffe JD, Cho S. The

477 relationship of breakfast skipping and type of breakfast consumption with nutrient intake and

478 weight status in children and adolescents: the National Health and Nutrition Examination Survey

479 1999-2006. J Am Diet Assoc. 2010; 110(6): 869-878.

480 4. U.S. Department of Agriculture. Nutrition Standards in the National School Lunch and School 481 Breakfast Programs; Final Rule. U.S. Government Publishing Office Wed site.

482 http://www.gpo.gov/fdsys/pkg/FR-2012-01-26/pdf/2012-1010.pdf. Updated January 16, 2012.

483 Accessed June 26, 2015.

484 5. Bhattacharya J, Currie J, Haider SJ. Breakfast of champions? The School Breakfast Program

485 and the nutrition of children and families. J Hum Resour. 2006; 41(3): 445-466.

486 6. Bartfield J, Myoung K, Ryu J, Ahn H. The School Breakfast Program Participation and

487 Impacts: Electronic Report from the Economic Research Service. University of Wisconsin

488 Extension Web site. http://fyi.uwex.edu/wischoolbreakfast/files/2009/10/The-School-Breakfast-

489 Program-Participation-and-Impacts1.pdf. Updated July 2009. Accessed June 26, 2015. 
490 7. Moore Q, Hulsey L, Ponza M. Factors Associated with School Meal Participation and the 491 Relationship between Different Participation Measures: Final Report. National Agricultural 492 Library Digital Collections Web site. http://naldc.nal.usda.gov/download/35701/PDF. Updated 493 June 2009. Accessed June 26, 2015.

494 8. Larson N, Wang Q, Berge JM, Shanafelt A, Nanney MS. Eating breakfast together as a 495 family: Mealtime experiences and associations with dietary intake among adolescents in rural 496 Minnesota, USA. Pub Health Nutrition. 2016; 19(9): 1565-1574

497 9. Food Research and Action Center. National and State Program Data. Food Research and 498 Action Center Web site. http://frac.org/reports-and-resources/national-and-state-program-data-2/.

499 Updated February 2015. Accessed June 26, 2015.

500 10. U.S. Department of Agriculture, Food and Nutrition Service. School Breakfast Program 501 Participation and Meals Served. USDA Food and Nutrition Service Web site.

502 http://www.fns.usda.gov/pd/sbsummar.htm. Updated June 5, 2015. Accessed June 26, 2015.

503 11. Woo N, Hewins J, Burke M. School Breakfast Scorecard: 2013-2014 School Year. Food 504 Research and Action Center Web site.

505 http://frac.org/pdf/School_Breakfast_Scorecard_SY_2013_2014.pdf. Updated February 2015. 506 Accessed June 26, 2015.

507 12. Food Research and Action Center. School breakfast scorecard: 2003. Food Research and 508 Action Center Web site. http://frac.org/wp-content/uploads/2009/09/2003breakfast.pdf. Updated 509 November 2003. Accessed June 26, 2015.

510 13. McDonnell E, Probard C, Weirich E, Hartman T, Birkenshaw P. School breakfast programs: 511 Perceptions and barriers. J Child Nutr Manag. 2004; 28. 
512 14. Hearst MO, Shanafelt A, Wang Q, Leduc R, Nanney MS. Barriers, benefits and behaviors

513 related to breakfast consumption among rural adolescents. Journal of School Health.

$514 \quad 2016 ; 86(3): 187-194$.

515 15. Askelson NM, Golembiewski EH, DePriest AM, O’Neill P, Delger PJ, Scheidel CA. The

516 answer isn't always a poster: Using social marketing principles and concept mapping with high

517 school students to improve participation in school breakfast. Social Marketing Quarterly. 2015;

$518 \quad 21: 119-134$

519 16. U.S. Department of Agriculture, Food and Nutrition Service. School breakfast program:

520 Discover School Breakfast toolkit. USDA Food and Nutrition Service Web site.

521 http://www.fns.usda.gov/sbp/discover-school-breakfast-toolkit. July 1, 2014. Accessed June 26, 5222015.

523 17. Lambert L, Carr D. Focus group discussions with elementary school food service directors,

524 teachers, and parents regarding the school breakfast program. National Food Service

525 Management Institute Web site.

526 http://www.nfsmi.org/documentlibraryfiles/PDF/20080227095532.pdf. 2005. Accessed June 26, 5272015.

528 18. Bailey-Davis L, Virus A, McCoy T, Wojtanowski A, Vander-Veur S, Foster G. Middle 529 school student and parent perceptions of government-sponsored free school breakfast and 530 consumption: A qualitative inquiry in an urban setting. J Acad Nutr Diet. 2012; 113(2): 251-257.

531 19. Reddan J, Wahlstrom K, Reicks M. Children's perceived benefits and barriers in relation to 532 eating breakfast in schools with or without universal school breakfast. J Nutr Educ Behav. 2002; 533 34(1): 47-52. 
534 20. Bernstein L, McLaughlin J, Crepinsek MK, Daft L. Evaluation of the School Breakfast

535 Program Pilot Project: Final Report. Alexandria, VA: USDA, Food and Nutrition Service, Office

536 of Analysis, Nutrition, and Evaluation. 2004. Nutrition Assistance Program Report Series, No.

537 CN-04-SBP.

538 21. Lu D, Larsen M. Small area estimation in a survey of high school students in X. Proceedings

539 of the Survey Research Methods Section. Alexandria, VA: American Statistical Association;

540 2007. https://www.amstat.org/sections/srms/proceedings/y2007/Files/JSM2007-000066.pdf.

$541 \quad$ Accessed June 26, 2015.

542 22. Identification of rural locales. National Center for Education Statistics Web site.

543 https://nces.ed.gov/ccd/rural_locales.asp. Accessed June 26, 2015.

544 23. SAS Institute Inc., SAS 9.1.4, Cary, NC: SAS Institute Inc., 2013.

545 24. Allison PD. Imputation of categorical variables with PROC MI.

546 http://www2.sas.com/proceedings/sugi30/113-30.pdf Accessed July 20, 2016

547 25. Zeger SL, Liang KY. Longitudinal Data Analysis for Discrete and Continuous Outcomes.

548 Biometrics. 1986; 42(1) 121-30.

549 26. Liang KY, Zeger SL. Longitudinal Data Analysis Using Generalized Linear Models.

$550 \quad$ Biometrika. 1986; 73(1) 13-22.

551 27. Pan W. Akaike's Information Criterion in Generalized Estimating Equations. Biometrics.

552 2001; 57(1) 120-25.

553 28. Wong K. Evaluation of the 2005-2006 Provision 2 Pilot in Milwaukee 
554 Public Schools. Congressional Hunger Center Web site. http://hungercenter.wpengine.netdna555 cdn.com/wp-content/uploads/2011/07/Evaluation-of-Provision-2-Pilot-in-Milwaukee-Wong.pdf.

556 February 2006. Accessed June 26, 2015.

557 29. Imberman SA, Kugler AD. The effect of providing breakfast on student performance:

558 Evidence from an in-class breakfast program. http://www.nber.org/papers/w17720.pdf. National

559 Bureau of Economic Research working paper 17720. January 2012. Accessed June 26, 2015.

560 30. Golembiewski EH, Askelson NM, Elchert DM, Leicht EA, Scheidel CA, Delger PJ. From

561 policy to practice: Parent perceptions of the 2010 Federal School Lunch Mandate. J Child Nutr

$562 \quad$ Manag. 2015; 39(1)

563

564

565

566

567

568

569

570

571

572 
573 Table 1. Descriptive statistics from sample of parents included in the analysis $(n=7,209)$

\begin{tabular}{|c|c|c|c|c|c|c|}
\hline & \multicolumn{2}{|l|}{ Rural } & \multicolumn{2}{|l|}{ Urban } & \multicolumn{2}{|l|}{ Total } \\
\hline Variable & $\mathrm{n}(\%)$ & $\begin{array}{c}\text { Mean } \\
\text { (SD) }\end{array}$ & Count & $\begin{array}{c}\text { Mean } \\
\text { (SD) }\end{array}$ & Count & $\begin{array}{c}\text { Mean } \\
\text { (SD) }\end{array}$ \\
\hline School Breakfast Participation & $3974(45.32 \%)$ & & $3144(30.60 \%)$ & & $7209(38.80 \%)$ & \\
\hline Missing & 388 & & 278 & & 673 & \\
\hline \multicolumn{7}{|l|}{ School District Size } \\
\hline Large $>2500$ & $256(6.44 \%)$ & & $1764(56.11 \%)$ & & $2020(28.02 \%)$ & \\
\hline Medium 1000-2499 & $1035(26.04 \%)$ & & $1168(37.15 \%)$ & & $2203(30.56 \%)$ & \\
\hline Small < 1000 & $2479(62.38 \%)$ & & $193(6.14 \%)$ & & $2672(37.06 \%)$ & \\
\hline Missing & 204 & & 19 & & 314 & \\
\hline SB intended to help parents w/no time & $3974(48.62 \%)$ & & $3144(48.19 \%)$ & & $7209(48.48 \%)$ & \\
\hline Missing & 0 & & 0 & & 0 & \\
\hline SB intended to help parents w/ no money & $3974(46.75 \%)$ & & $3144(52.16 \%)$ & & $7209(49.38 \%)$ & \\
\hline Missing & 0 & & 0 & & 0 & \\
\hline SB intended to help parents who not care & $3974(31.81 \%)$ & & $3144(33.78 \%)$ & & $7209(32.70 \%)$ & \\
\hline Missing & 0 & & 0 & & 0 & \\
\hline SB intended to help student athletes & $3974(23.25 \%)$ & & $3144(18.70 \%)$ & & $7209(21.36 \%)$ & \\
\hline Missing & 0 & & 0 & & 0 & \\
\hline SB intended to help all children & $3974(51.16 \%)$ & & $3144(43.42 \%)$ & & $7209(47.68 \%)$ & \\
\hline Missing & 0 & & 0 & & 0 & \\
\hline \multicolumn{7}{|l|}{ Importance of SB } \\
\hline Can be skipped & $141(3.55 \%)$ & & $135(4.30 \%)$ & & $280(3.89 \%)$ & \\
\hline Important but my child not eat it everyday & $717(18.04 \%)$ & & $508(16.16 \%)$ & & $1242(17.23 \%)$ & \\
\hline Just as important as other meals & $1692(42.58 \%)$ & & $1384(44.02 \%)$ & & $3115(43.21 \%)$ & \\
\hline Most Important & $1076(27.08 \%)$ & & $878(27.93 \%)$ & & $1978(27.44 \%)$ & \\
\hline Missing & 348 & & 239 & & 594 & \\
\hline \multicolumn{7}{|l|}{ Is SB Healthy } \\
\hline I don't know & $1092(27.48 \%)$ & & $1125(35.78 \%)$ & & $2241(31.09 \%)$ & \\
\hline
\end{tabular}




\begin{tabular}{|c|c|c|c|c|c|c|}
\hline No & $608(15.30 \%)$ & & $521(16.57 \%)$ & & $1139(15.80 \%)$ & \\
\hline Yes & $1722(43.33 \%)$ & & $1076(34.22 \%)$ & & $2845(39.46 \%)$ & \\
\hline Missing & 552 & & 422 & & 984 & \\
\hline District Free/Reduced Percent & 3974 & $\begin{array}{l}31.59 \\
(12.01) \\
\end{array}$ & 3144 & $\begin{array}{l}37.15 \\
(11.40) \\
\end{array}$ & 7209 & $\begin{array}{c}34.06 \\
(12.06) \\
\end{array}$ \\
\hline Missing & 37 & & 0 & & 128 & \\
\hline $\begin{array}{l}\text { Total Score Benefits Questions (range 0- } \\
\text { 11) }\end{array}$ & 3974 & $\begin{array}{c}1.90 \\
(2.12)\end{array}$ & 3144 & $\begin{array}{l}1.74 \\
(2.10)\end{array}$ & 7209 & $\begin{array}{c}1.83 \\
(2.12)\end{array}$ \\
\hline Missing & 17 & & 10 & & 29 & \\
\hline Grade & 3974 & $\begin{array}{c}7.06 \\
(3.42)\end{array}$ & 3144 & $\begin{array}{c}6.82 \\
(3.46) \\
\end{array}$ & 7209 & $\begin{array}{c}6.96 \\
(3.44) \\
\end{array}$ \\
\hline 1 & $245(6.17 \%)$ & & $202(6.42 \%)$ & & $451(6.26 \%)$ & \\
\hline 2 & $282(7.10 \%)$ & & $269(8.56 \%)$ & & $557(7.73 \%)$ & \\
\hline 3 & $295(7.42 \%)$ & & $248(7.89 \%)$ & & $548(7.60 \%)$ & \\
\hline 4 & $287(7.22 \%)$ & & $259(8.24 \%)$ & & $553(7.67 \%)$ & \\
\hline 5 & $241(6.06 \%)$ & & $236(7.51 \%)$ & & $488(6.77 \%)$ & \\
\hline 6 & $324(8.15 \%)$ & & $226(7.19 \%)$ & & $557(7.73 \%)$ & \\
\hline 7 & $315(7.93 \%)$ & & $251(7.98 \%)$ & & $569(7.89 \%)$ & \\
\hline 8 & $394(9.91 \%)$ & & $253(8.05 \%)$ & & $657(9.11 \%)$ & \\
\hline 9 & $377(9.49 \%)$ & & $269(8.56 \%)$ & & $658(9.13 \%)$ & \\
\hline 10 & $414(10.42 \%)$ & & $342(10.88 \%)$ & & $760(10.54 \%)$ & \\
\hline 11 & $413(10.39 \%)$ & & $308(9.80 \%)$ & & $730(10.13 \%)$ & \\
\hline 12 & $387(9.74 \%)$ & & $281(8.94 \%)$ & & $681(9.45 \%)$ & \\
\hline Missing & 0 & & 0 & & 0 & \\
\hline
\end{tabular}

$\mathrm{SD}=$ standard deviation, $\mathrm{SB}=$ school breakfast 
575 Table 2: Generalized Estimating Equation demonstrating associations with school breakfast 576 participation

\begin{tabular}{|c|c|c|}
\hline Predictor & Estimate & $\begin{array}{l}\text { Standard } \\
\text { Error }\end{array}$ \\
\hline Intercept & $-1.825 * * *$ & 0.263482 \\
\hline Size of district (large) & 0.266 & 0.251627 \\
\hline Size of district (medium) & -0.232 & 0.196701 \\
\hline Size of district (small) & 0 & \\
\hline District free/reduced proportion & $0.014 * * *$ & 0.004112 \\
\hline Total score of benefits questions & $0.382 * * *$ & 0.016822 \\
\hline School breakfast intended to help (parents no time) & $-0.316 * * *$ & 0.073080 \\
\hline School breakfast intended to help (parents no money) & $-0.2866 * * *$ & 0.076637 \\
\hline $\begin{array}{l}\text { School breakfast intended to help (parents who don't } \\
\text { care) }\end{array}$ & $-0.4266 * * *$ & 0.080107 \\
\hline School breakfast intended to help (student athletes) & $0.3536 * * *$ & 0.082263 \\
\hline School breakfast intended to help (all children) & 0.0266 & 0.066926 \\
\hline Urban & $-0.6106 * * *$ & 0.183926 \\
\hline SB district participation rate & - & - \\
\hline Importance breakfast (Most important) & $0.675 * * *$ & 0.154930 \\
\hline Importance breakfast (Important but not eat) & $0.523 * *$ & 0.159629 \\
\hline Importance breakfast (Important as other meals) & 0.284 & 0.152687 \\
\hline Importance breakfast (Can be skipped) & 0 & \\
\hline Grade & 0.018 & 0.014643 \\
\hline Is school breakfast healthy (No) & $0.327 * *$ & 0.117063 \\
\hline Is school breakfast healthy (Yes) & $0.533 * * *$ & 0.084532 \\
\hline Is school breakfast healthy (I don't know) & 0 & \\
\hline Grade* Size of district (large) & $-0.079 * *$ & 0.023882 \\
\hline Grade* Size of district (medium) & 0.004 & 0.021136 \\
\hline Grade*Size of district (small) & 0 & \\
\hline Is school breakfast healthy (Yes) * Urban & $0.340 * *$ & 0.117183 \\
\hline Is school breakfast healthy (No) * Urban & 0.273 & 0.167667 \\
\hline
\end{tabular}


578 Table 3. Interaction between parent perception of school breakfast being healthy and urban/rural

\begin{tabular}{cccc}
\hline & & Urban $(\mathrm{CI})$ & Rural (CI) \\
\hline Is school & Yes & $0.262(-0.101,0.625)$ & $0.533(0.368,0.699)$ \\
breakfast & No & $-0.010(-0.405,0.384)$ & $0.327(0.098,0.557)$ \\
\cline { 2 - 4 } healthy? & I don't know & $-0.610(-0.971,-0.250)$ & 0 \\
\hline
\end{tabular}

579

580

581 


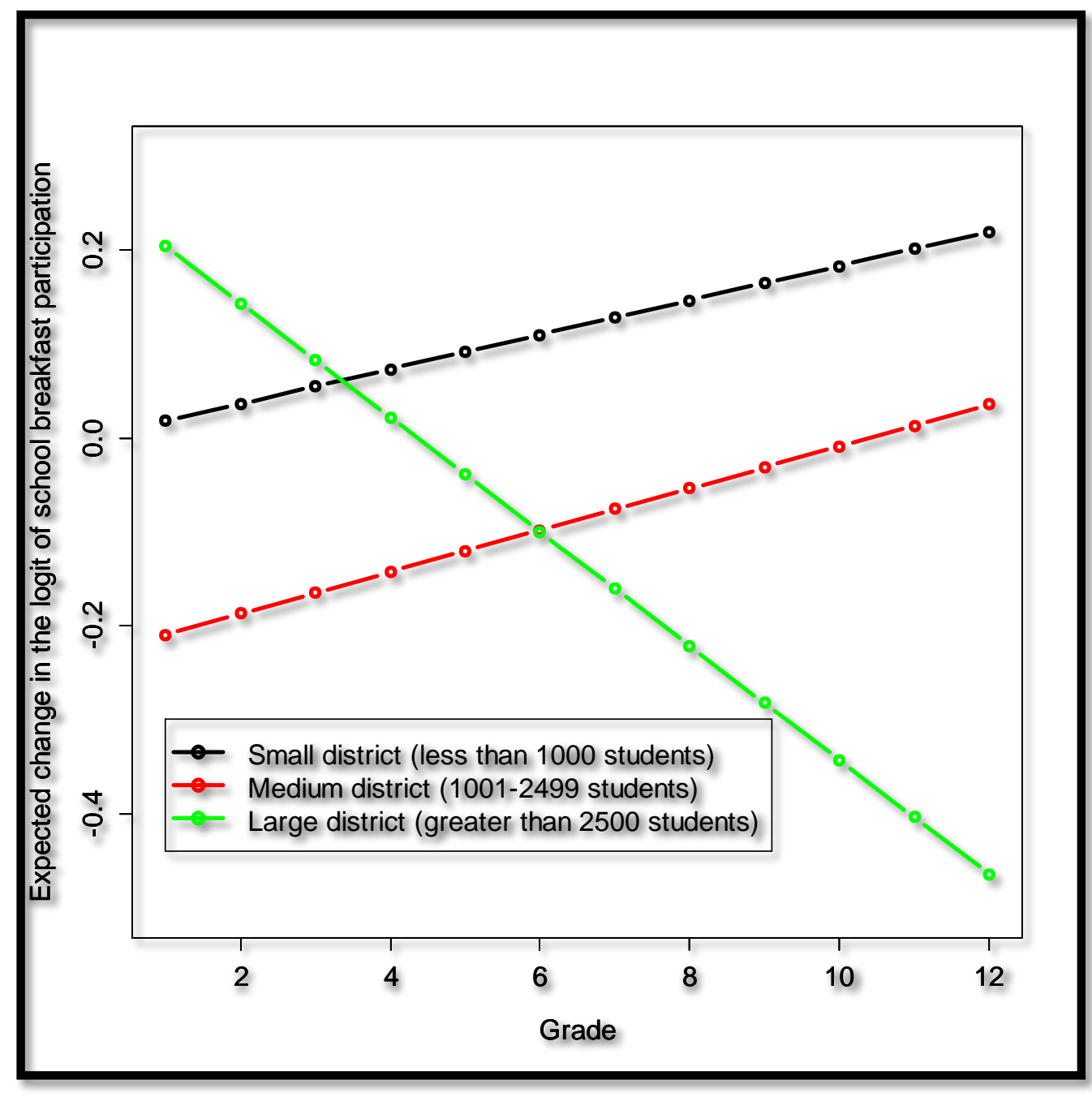

583

584 Figure 1. Expected Change in the Logit of School Breakfast Participation 